\title{
Seepage Calculation and Analysis of Xinxiang Town Landslide under Rainfall Condition
}

\author{
Yunyun Fan ${ }^{1, a}$, Fengyuan $\mathrm{Wu}^{1, \mathrm{~b}}$ and Li Liang1, c \\ ${ }^{1}$ Key Laboratory of Ministry of Education on Safe Mining of Deep Metal Mines, Northeastern \\ University, Shenyang, 110004, China \\ ayunyunfan@126.com, b356377199@qq.com, cliangli@mail.neu.edu.cn
}

\begin{abstract}
Keywords: Xinxiang Town landslide, rainfall infiltration, seepage calculation
Abstract. The seepage process of Xinxiang Town landslide under typical rainfall condition was calculated and analyzed in this paper. The calculation results show that the rainfall can significantly raise the saturation line of landslide and form the saturated seepage zone with relatively large hydraulic gradient in the original unsaturated surface soil, and the landslide stability decreases consequently. A comprehensive evaluation of the landslide stability can also be done by combining with the calculation of strain and stress. Meanwhile, although retaining wall and other engineering measures can effectively enhance the landslide stability, the retaining wall may block the drainage channel due to the concentrated seepage water pressure. For this reason, it is important to ensure the engineering quality and the drainage measures at the same time.
\end{abstract}

\section{Project Overview}

Xinxiang Town landslide, located in Wanzhou District of Chongqing city, within the influence scope of the water level of the Three Gorges Project, is semi-submerged at normal storage water level of the Three Gorges. The landslide area is in the lower part of the slope on the right bank of the Yangtze River and between the elevation $154.67-214.97 \mathrm{~m}$, with the terrain higher in north lower in south and the slope to north by west. The landslide reaches out to the sandstone cliffs behind the original Xinxiang Primary School on the north, the ring road of Xinxiang Town on the south, and the sewage ditches of main town on the east and west. The landslide is $350 \mathrm{~m}$ from north to south and $120 \mathrm{~m}$ from east to west, and covers an area of $42000 \mathrm{~m}^{2}$. The average thickness of the sliding body is $8.17 \mathrm{~m}$ and the volume $343140 \mathrm{~m}^{3}$.

The Xinxiang Town landslide is a kind of soil landslide, which is the interaction result of topography, lithology and water. In the landslide area, the quaternary eluvial material is mainly composed of soft plastic and plastic-like silty clay. The slide surface is the weak structural plane between the quaternary soil and bedrock on which there are some obvious scratches, while the slide bed is mostly composed of sandstone and mudstone. The landslide deformation is mainly presented as building cracking and ground cracking. With the steady entrainment and cutting action of the Yangtze River, the topographic slope height and slope angle are gradually increased, which provides the topography and geomorphology conditions for the formation of landslide. The groundwater under landslide area is mainly loose rock pore water. The landslide debris and eluvial materials are deposited on the slope, which facilitates the discharge of surface water and groundwater. The landslide area borders on the Yangtze River where there is also large and concentrated rainfall. The infiltration of rainwater, by reducing the soil shear strength and increasing the soil weight, may lead to slope failure under hydrodynamic pressure [1-5].

The rear landslide is a densely built area belonging to the Xinxiang Town of Wanzhou District. As a new immigrant town in the reservoir area of Three Gorges Project, the Xinxiang Town has also a negative impact on the local stability of the landslide due to its urban construction. In recent years, the landslide deformation in this area has been intensified and poses a serious threat to the people's lives and the safety of national properties. Therefore, the landslide control is an urgent and long-term task. The seepage process of Xinxiang Town landslide under typical rainfall condition was calculated and analyzed in this paper. 


\section{Seepage Calculation and Analysis of Xinxiang Town Landslide}

Based on the relevant information, the main section of Xinxiang Town landslide under typical rainfall condition was calculated and analyzed, and the change laws and the characteristics of seepage field under rainfall condition were also discussed, which provides references for further reasonable drainage and reinforcement engineering.

According to the preliminary design of the Xinxiang Town landslide, the anti-slide pile engineering was laid at the elevation of $188-190 \mathrm{~m}$. The distance between pile centers is $6 \mathrm{~m}$, the section of pile is $2 \mathrm{~m}^{*} 3 \mathrm{~m}$, the pile length is $28 \mathrm{~m}$ of which the embedded length is $9 \mathrm{~m}$, the total number of piles is 76 . A concrete retaining wall of $13 \mathrm{~m}$ high and $139 \mathrm{~m}$ long was set at the elevation of $175 \mathrm{~m}$ along the landslide area, and drainage ditches with a trapezoidal cross section was dug along the landslide boundary in accordance with the terrain features around the landslide area.

According to the characteristics of geological and protective structures of the Xinxiang Town landslide, the landslide body has been divided into 11 partitions, including surface soil, sliding zone, anti-slide pile and retaining wall, etc. The section of geological structure, protective structure and the materials of different partitions are shown in Fig.1 and Table 1.

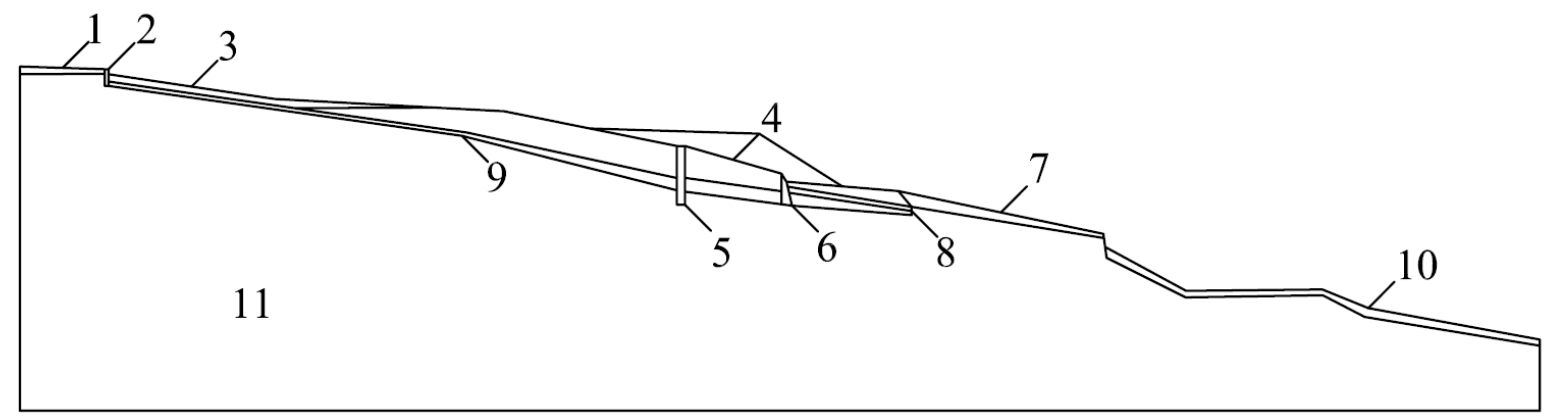

Fig.1 The geological structure of the Xinxiang Town landslide

The permeable partition of this section was achieved according to the seepage experimental results and the survey data, the permeability parameters as shown in Table 1 were used in the calculation:

Table 1 Permeability parameters of the Xinxiang Town landslide

\begin{tabular}{cccc}
\hline Material & $\begin{array}{c}\text { Permeability } \\
\text { Parameters [m/d] }\end{array}$ & Material & $\begin{array}{c}\text { Permeability } \\
\text { Parameters [m/d] }\end{array}$ \\
\hline 1 Surface soil & 0.5 & 7 Surface soil & 0.5 \\
2 Retaining wall & 0.001 & 8 Surface soil & 0.5 \\
3 Surface soil & 0.5 & 9 Sliding zone & 0.2 \\
& & 10 Alluvial soil of & 0.002 \\
4 Surface soil & 0.5 & reservoir area & 0.1 \\
5 Anti-slide pile & 0.001 & 11 Deep soil & \\
6 Retaining wall & 0.001 & & \\
\hline
\end{tabular}

According to the site survey data, the value of upstream head is $179 \mathrm{~m}$ and the downstream head is $175 \mathrm{~m}$. The bottom boundary is impervious and the upstream of slope is water infiltration boundary.

When calculating, the saturated seepage period without rainfall was set to 100 days, and 10 periods among 11 time points were selected to calculate the unsaturated seepage field. The 10 periods are respectively 1 hour, 1 hour, 1 hour, 1 hour, 1 hour, 2 hours, 2 hours, 4 hours, 24 hours, 120 hours and 240 hours. The rainfall capacity at the 11 time points are respectively $0 \mathrm{~mm}, 0 \mathrm{~mm}, 5 \mathrm{~mm}, 20 \mathrm{~mm}$, $10 \mathrm{~mm}, 7 \mathrm{~mm}, 5 \mathrm{~mm}, 0 \mathrm{~mm}, 0 \mathrm{~mm}, 0 \mathrm{~mm}, 0 \mathrm{~mm}$.

The calculation results of seepage field at several typical time points under rainfall condition were obtained as shown in Fig.2 Fig.7, where the shaded area represents the unsaturated zone. 


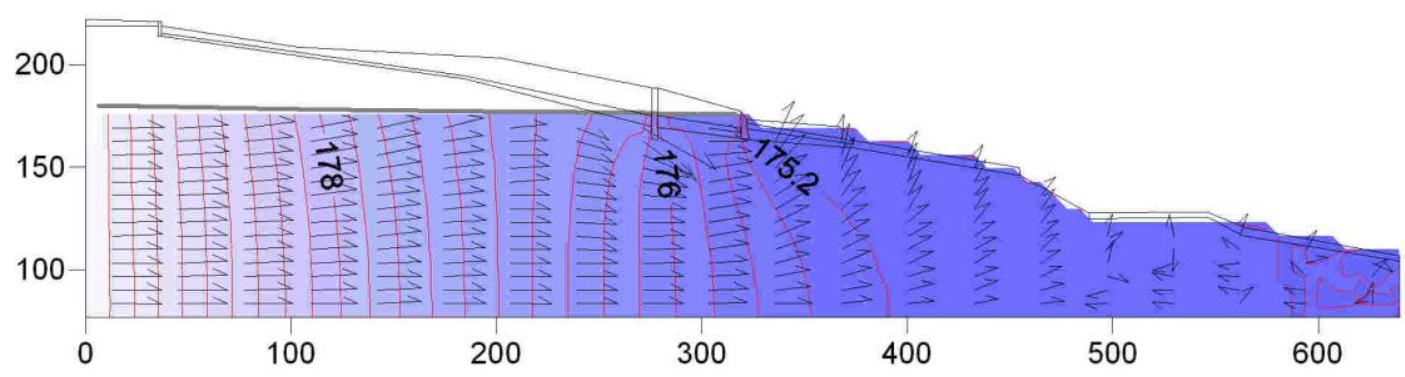

Fig.2 Initial steady seepage field of landslide

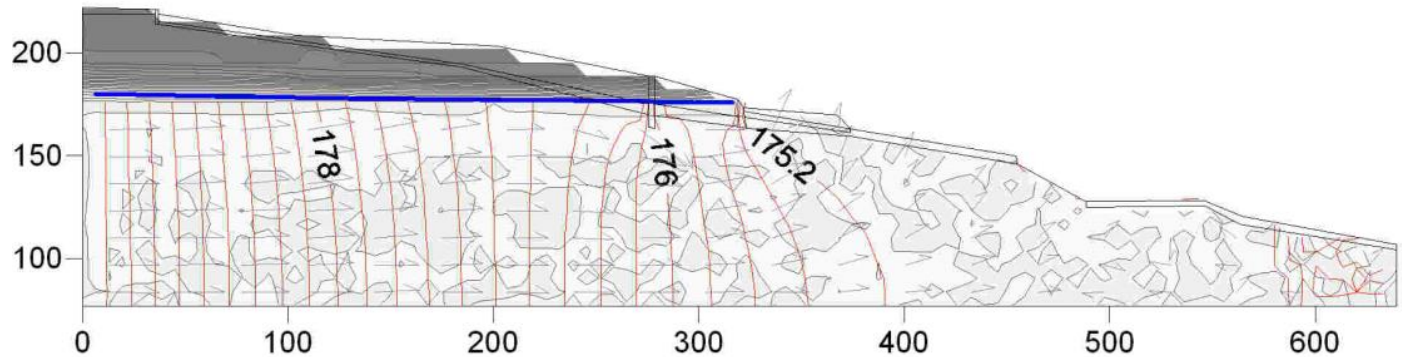

Fig. 3 Landslide seepage field at the 1 st time point

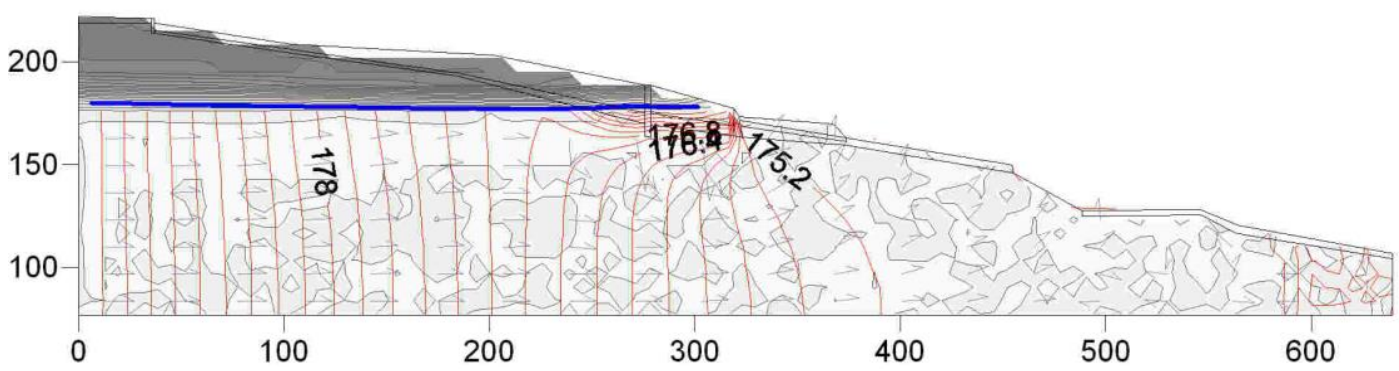

Fig.4 Landslide seepage field at the 3rd time point

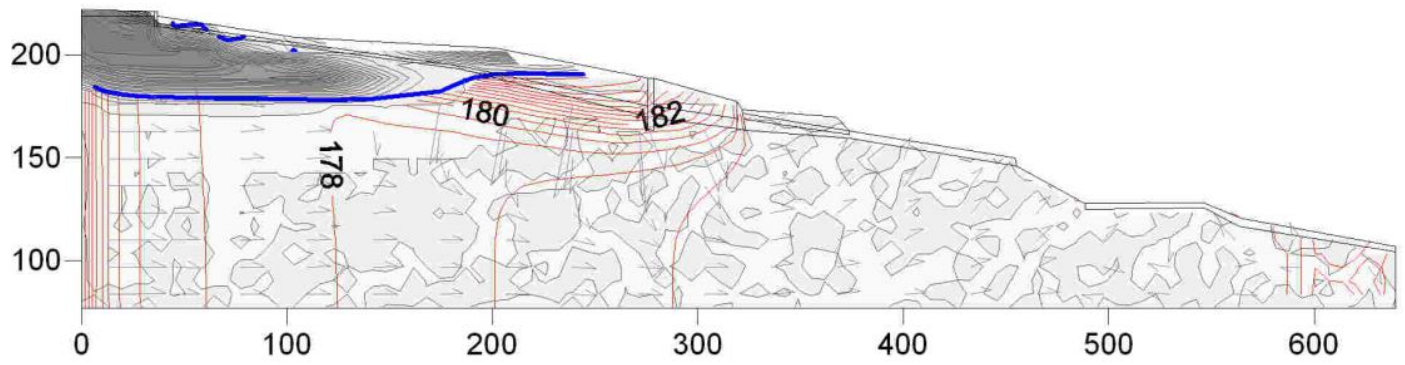

Fig.5 Landslide seepage field at the 5th time point

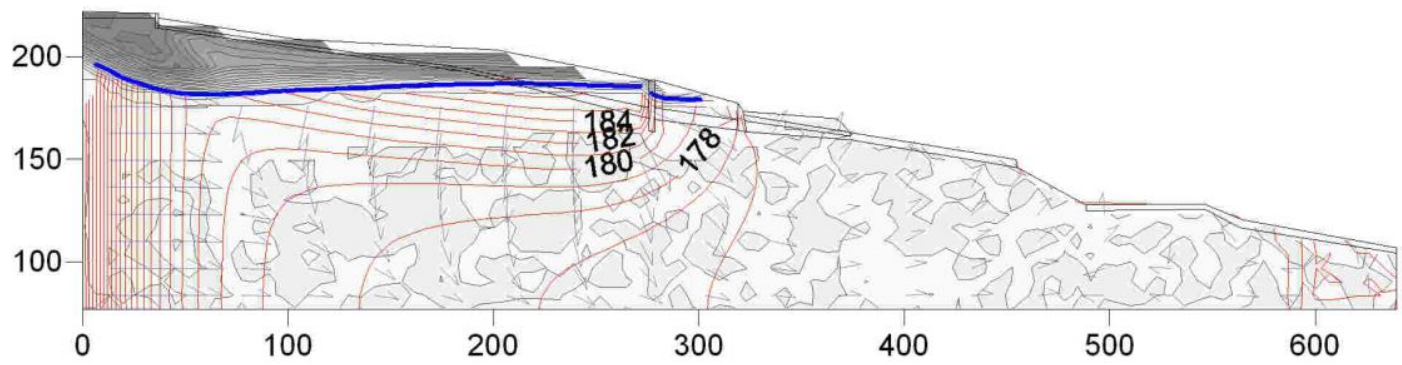

Fig.6 Landslide seepage field at the 8th time point

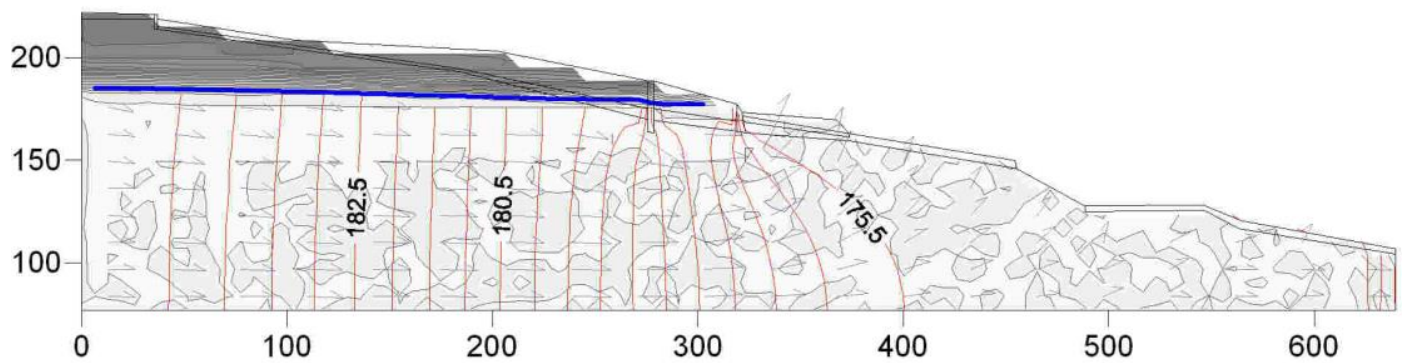

Fig.7 Landslide seepage field at the 11th time point 
It can be seen from the results that the seepage field at different time points has similar characteristics, the head contour line decreases regularly from upstream to downstream and the equal headline bending appears at stratigraphic boundary. These characteristics are consistent with the actual seepage situation. Under the calculation conditions of this paper, the water of the Three Gorges reservoir submerged the lower part of the landslide weak zone, and there was seepage water around the anti-slide piles as well as the retaining wall. The water-level contours are relatively dense. The high hydraulic gradient region is mainly concentrated around the upstream boundary, the middle part of the weak zone, the anti-slide piles and the retaining wall. With the progress of rainfall, the vertical rainwater infiltration brought an incessant rise of the saturation line and a reduction of unsaturated zone. The saturated seepage zone with relatively large hydraulic gradient appeared in the original unsaturated surface soil. At this moment, the increasing seepage water pressure and the decreasing soil strength may lead to the landslide failure, which poses a serious threat to the people's lives and properties in the landslide area. With the fall of groundwater after the rain, the landslide seepage field will eventually return to the original stable state. It can be seen from the calculation results that the protection method with the combination of anti-slide piles and the retaining wall applied in this paper seems reasonable and economical for the shallow landslide with relatively complete bedrock and relatively smooth sliding surface, but the retaining wall with low permeability parameters blocked the drainage channel, so the drainage project is also significant to the retaining wall engineering. At the same time, some other engineering measures such as load shedding and pressing foot can also be adopted to improve the landslide stability.

\section{Conclusion}

The seepage process of Xinxiang Town landslide under typical rainfall condition is calculated and analyzed in this paper, and the calculation results show that with the progress of rainfall, the unsaturated zone is reduced and the saturation line is elevated. The saturated seepage zone appears in the original unsaturated surface soil. Under the dual role of the increasing seepage water pressure and the decreasing soil strength, the landslide enters a dangerous state. Therefore, it is necessary to calculate the seepage process under different typical rainfall and make a comprehensive evaluation of the landslide stability by combining with the calculation of strain and stress. Meanwhile, the calculations also show that although retaining wall and other engineering measures can effectively enhance the stability of the landslide, the retaining wall may hinder the drainage channel due to the concentrated seepage water pressure. For this reason, it is important to ensure the engineering quality and the drainage measures at the same time.

\section{Acknowledgements}

This work is supported by the National Natural Science Foundation of China (Grant No. 41201007, 51474048), the Opening fund of State Key Laboratory of Geohazard Prevention and Geoenvironment Protection of Chengdu University of Technology (Grant No. Sklgp2012K010), the Fundamental Research Funds for the Central Universities of China (Grant No. N130401003, L1501009), and the Research Fund for General Science Project of Department of Education of Liaoning Province (Grant No. L2013103).

\section{References}

[1] Longbo Huang, Hongxing Wang, Yunzhi Tan, Jun Wu:Journal of China Three Gorges University(Natural Sciences).Vol.38(2016), p.40-45.[In Chinese]

[2] Hongqiang Dou, Tongchun Han, Xiaonan Gong, Zhining Li, Ziyi Qiu:Rock and Soil Mechanics, Vol. 37(2016), p.1144-1152.[In Chinese] 
[3] Xiaojie Yang, Dinggui Hou, Zhenli Hao, Zhigang Tao, Haiyang Shi, Gun Qi: Chinese Journal of Rock Mechanics and Engineering.Vol. 35(2016), p.3232-3240. [In Chinese]

[4] Huijuan Meng:Haihe Water Resources. Vol. 35(2016), p.50-52. [In Chinese]

[5] Shiguo Ma, Tongchun Han, Riqing Xu, Weiwen Deng:Journal of Central South University(Science and Technology). Vol. 60(2015), p.2673-2678. [In Chinese] 